\title{
Pounding Dynamic Responses of Sliding Base-Isolated Rectangular Liquid-Storage Structure considering Soil-Structure Interactions
}

\author{
Xuansheng Cheng, ${ }^{1,2}$ Wei Jing, ${ }^{1,2}$ Jia Chen, ${ }^{1,2}$ and Xiaoyan Zhang ${ }^{1,2}$ \\ ${ }^{1}$ Key Laboratory of Disaster Prevention and Mitigation in Civil Engineering of Gansu Province, Lanzhou University of Technology, \\ Lanzhou 730050, China \\ ${ }^{2}$ Western Engineering Research Center of Disaster Mitigation in Civil Engineering of Ministry of Education, \\ Lanzhou University of Technology, Lanzhou 730050, China
}

Correspondence should be addressed to Xuansheng Cheng; chengxuansheng@gmail.com and Wei Jing; jingwei3276@163.com

Received 18 August 2016; Revised 19 December 2016; Accepted 4 January 2017; Published 31 January 2017

Academic Editor: Ivo Caliò

Copyright ( 12017 Xuansheng Cheng et al. This is an open access article distributed under the Creative Commons Attribution License, which permits unrestricted use, distribution, and reproduction in any medium, provided the original work is properly cited.

\begin{abstract}
The soil-structure interaction (SSI) is simulated by an artificial boundary, the pounding that occurs between the sliding base-isolated rectangular liquid-storage structure (LSS) and the surrounding moat wall is considered, the instantaneous pounding is simulated using the Hertz-damp model, and a simplified mechanical model with two particles and four degrees of freedom is established. Dynamic equation is obtained using Hamilton principle; effects of SSI, initial gap, and friction coefficient on the pounding responses under the action of near-field pulse-like Chi-Chi earthquake and far-field Imperial Valley-06 earthquake are studied. The results show that SSI will amplify liquid sloshing height but that structural acceleration and impact force will be reduced because of SSI. The responses caused by Chi-Chi earthquake are far greater than those of Imperial Valley-06 earthquake. Initial gap has a small effect on liquid sloshing height; structural acceleration and impact force first increase as the initial gap increases and then begin to decrease; in the design of moat wall of sliding isolation LSS, a certain gap exists that will more adversely affect the pounding responses of structure. Liquid sloshing height is less affected by coefficient of friction, but structural acceleration and impact force decrease as friction coefficient increases in general.
\end{abstract}

\section{Introduction}

In lifeline engineering, liquid-storage structures play irreplaceable roles in the development of a national economy, but many earthquakes have caused different degrees of damage to the liquid-storage structures. Because of the uniqueness of this type of structure, failure causes some types of disaster, such as a fluid leakage, fire, or environment pollution. An effective means to improve the seismic capacity for this structure is a special base isolation structure that has been used widely. One of the main shock absorption measures is rubber isolation, which can reduce dynamic responses, such as base shear, overturning moment, and wall internal force, of the liquid-storage structure, but its effect on liquid sloshing is very limited and may even produce the opposite effect
[1-4]. However, some new types of sliding isolation methods can achieve independence of the isolation period and liquid sloshing period [5] and avoid the resonance phenomenon, which can reduce both the structural dynamic responses and liquid sloshing simultaneously $[6,7]$. Therefore, if this design is reasonable, the effect of this sliding base-isolated technology will be better than rubber base isolation $[8,9]$.

Although the sliding isolation measure can effectively reduce the structure dynamic responses, one characteristic of a sliding isolation structure is that it will suffer a large horizontal displacement during an earthquake. For normal use and structural safety, it is very necessary to use a corresponding limiting displacement method. At present, a common method, the moat wall, is widely used in various types of base-isolated structures. Although the moat wall 
can control the base-isolated structure displacement [10], the pounding between the isolation structure and moat wall greatly affects the system dynamic responses. In recent years, some scholars have paid attention to the pounding problem of the base-isolated structure caused by an earthquake and have achieved certain results. Nagarajaiah and Sun [11] assessed the dynamic responses of a base-isolated structure used for a fire control command, which was destroyed because of structure and moat wall pounding during the 1994 Northridge earthquake. The results showed that the pounding increased the base-isolated structure dynamic responses. Matsagar and Jangid [12] assumed that pounding occurred only between the bottom of the structure and the moat wall and studied the pounding dynamic responses of a building with various isolation systems. Komodromos [13] concluded that the dynamic responses caused by pounding increased as the impact stiffness and isolation system stiffness increased based on numerical simulations. Fu et al. [14] determined that the dynamic responses caused by pounding could change the basic mode of the base-isolated structure and excite a higher mode of the structure. Masroor and Mosqueda [15] considered the moat wall flexibility in a pounding model of an isolated structure and found that the moat wall characteristics greatly influenced the amplification of the dynamic response and degree of damage. Pant and Wijeyewickrema [16] considered different earthquake excitations and found that the pounding effect had a significant effect on the performance of an isolated structure. Fan et al. [17] studied the vulnerability of an isolation structure with a moat wall and determined that the structure mass and mechanical parameters of an isolation bearing had a greater effect on the maximum base displacement. Khatiwada and Chouw [18] noted that the impact stiffness and coefficient of restitution were the main factors influencing the pounding responses.

The foundation effect is not considered in the above studies when the base-isolated structure collides with the moat wall, but the SSI has a significant effect on the vibrational frequency [19], the system damping ratio and rotational displacement of the foundation [20], the structural dynamic responses [21], and the reasonable choice of the isolation bearing [22] of an isolation structure. Currently, studies of the SSI on the pounding dynamic responses of a structure are very limited [23]. Chau et al. [24] noted that the vibrational response of the structure could be amplified but that the SSI could suppress the vibrational response caused by pounding. Mahmoud and Gutub [25] found that the SSI effect had a more significant effect on isolated buildings located on a soft soil, and the SSI effect could increase the number of collisions between the structure and surrounding moat wall. Shakya and Wijeyewickrema [26] used the gap element and KelvinVoigt model to simulate the pounding problem and found that the dynamic responses of the structure will be reduced when the foundation is considered.

In summary, the effect of the SSI on the structural dynamic responses is obvious. Although the probability of pounding of the sliding base-isolated structure with the moat wall is larger than the rubber isolation, studies on the dynamic responses of a sliding isolation structure that consider the SSI have not been performed. The spring-mass model is used to simulate the coupling problem of the sliding base-isolated liquid-storage structure, and the $2 \mathrm{D}$ viscoelastic artificial boundary is used to simulate the foundation effect. A simplified mechanical model and the corresponding dynamic equations of the sliding isolation rectangular liquid-storage structure that consider the SSI and pounding are established, and the dynamic responses of the rectangular liquidstorage structure experiencing near-field pulse-like Chi-Chi earthquake and far-field Imperial Valley-06 earthquake are studied. Sliding isolation has a certain advantage in the shock absorption of a liquid-storage structure, and theoretical research on this type of damping method is helpful to its future application.

\section{Calculation Model}

2.1. Foundation Model. To consider the foundation effect, the lumped parameter model is used to simulate the elastic foundation and the discrete model, which is based on the theory of a homogeneous, isotropic, and elastic half space. Translation and rotation of the foundation are simulated using the spring element and damping element, respectively, and the corresponding parameters can be calculated by using the following equations [27]:

$$
\begin{aligned}
& k_{h}=2(1-v) G \beta_{x} \sqrt{B L}, \\
& c_{h}=0.576 k_{h} r_{h} \sqrt{\frac{\rho}{G}}, \\
& k_{r}=\frac{G}{1-\nu} \beta_{\varphi} B L^{2}, \\
& c_{r}=\frac{0.3}{1+\beta_{\varphi}} k_{r} r_{r} \sqrt{\frac{\rho}{G}},
\end{aligned}
$$

where $\nu$ is Poisson's ratio; $G$ is the shear modulus; and $\beta_{x}$ and $\beta_{\varphi}$ are the constants to correct the translation and rotation of the spring, respectively. $\beta_{x}$ and $\beta_{\varphi}$ have strong relationships with the foundation length-width ratio, and according to the existing literature [27], the approximate values of $\beta_{x}$ and $\beta_{\varphi}$ are equal to $1, L$ and $B$ are the foundation length and width, respectively, and $L$ and $B$ are parallel and perpendicular to the direction of earthquake, respectively. $\rho$ is soil density, and $r_{h}$ and $r_{r}$ are equivalent radii of the foundation that correspond to translation and rotation, respectively. The maximum shear modulus $G_{\max }$ is only suitable when the soil is in the low strain condition, and it can be expressed as a function of the shear wave velocity $V_{s}$ and soil density $\rho$

$$
G_{\max }=\rho\left(V_{s}\right)^{2}
$$

When the soil is in the inelastic stage, the shear modulus $G$ is significantly reduced. The shear modulus $G$ will be changed when the shear strain $\gamma$ is beyond the range of the elastic state because of a dynamic effect. To realistically simulate the ground effect, the shear modulus $G$ needs to be reduced by introducing the shear modulus reduction curve 
(G/Gmax - 1) [27], and the shear strain $\gamma$ can be expressed as

$$
\begin{aligned}
\gamma= & \frac{V}{4}\left(\frac{2}{\pi}\right)^{0.5}\left(\frac{3}{4 r^{2} 6 V_{s}^{2} \rho}\right) \\
\cdot & {\left[0.061+\left(\frac{0.18 r}{8}\right)+0.3026\right]+\frac{M}{4}\left(\frac{2}{\pi}\right)^{0.5} } \\
& \cdot\left(\frac{13.840 r_{r}}{32 r^{2} 6 V_{s}^{2} \rho}\right)
\end{aligned}
$$

where $V$ is the horizontal shear force and $M$ is the overturning moment.

2.2. Pounding Calculation Model. Sliding base-isolated liquid-storage structures will suffer large amounts of slippage under the action of some strong earthquakes. Thus, the pounding dynamic responses caused by pounding between the liquid-storage structure and moat wall are important subjects to study. The contact element method is an effective technique to simulate pounding problems; common pounding models include the linear model, Kelvin model, Hertz model, and Hertz-damp model [24, 28-31]. Muthumar and Desroches [29] concluded that, for the same parameters, the differences in the displacements and acceleration calculated by the different models are within 12\%. Chau et al. [24] and Jankowski [31] systematically compared the numerical and experimental results of the pounding models for different materials and showed that both the linear and nonlinear pounding models could satisfy the precision requirements for engineering.

Previous experimental studies have shown that the energy loss during the pounding process is mainly concentrated when the two objects are approaching each other but is relatively small during the recovery phase [32]. The modified Hertz model (Hertz-damp model), which is composed of nonlinear springs and a nonlinear damping element (Figure 1), is chosen to simulate the pounding. The model does not consider the energy loss in the pounding recovery phase and assumes that all of the energy loss caused by pounding occurs as the two objects approach each other [31]. The contact forces during the pounding and recovery phases can be expressed as (4) and (5), respectively.

The pounding occurs on the left:

$$
\begin{aligned}
& F_{p}=-k_{\mathrm{imp}}\left(-u_{b}-g_{p}\right)^{3 / 2}-c_{\mathrm{imp}} \dot{u}_{b} ; \\
& -u_{b}-g_{p}>0, \dot{u}_{b}<0 \\
& F_{p}=-k_{\text {imp }}\left(-u_{b}-g_{p}\right)^{3 / 2} ; \quad-u_{b}-g_{p}>0, \dot{u}_{b}>0 \\
& F_{p}=0 ; \quad-u_{b}-g_{p} \leq 0 .
\end{aligned}
$$

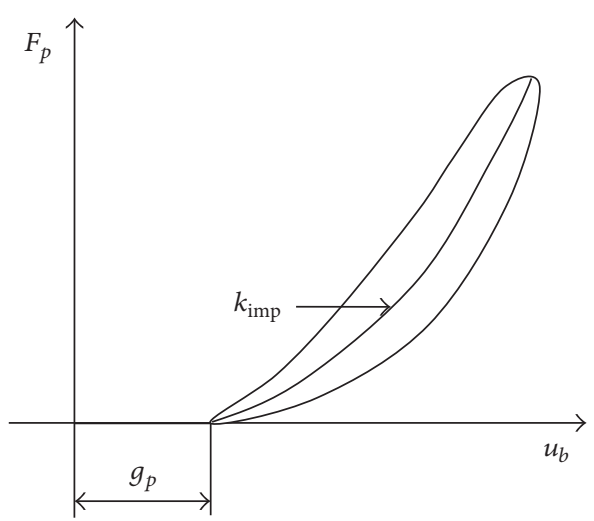

FIGURE 1: Hertz-damp pounding model.

The pounding occurs on the right:

$$
\begin{aligned}
& F_{p}=k_{\mathrm{imp}}\left(u_{b}-g_{p}\right)^{3 / 2}+c_{\mathrm{imp}} \dot{u}_{b} ; \quad u_{b}-g_{p}>0, \dot{u}_{b}>0 \\
& F_{p}=k_{\mathrm{imp}}\left(u_{b}-g_{p}\right)^{3 / 2} ; \quad u_{b}-g_{p}>0, \dot{u}_{b}<0 \\
& F_{p}=0 ; \quad u_{b}-g_{p} \leq 0,
\end{aligned}
$$

where $u_{b}$ is the horizontal displacement of the liquid-storage structure; $g_{p}$ is the initial gap between the structure and surrounding moat wall or restraining wall; $\dot{u}_{b}$ is the structural velocity; $k_{\text {imp }}$ is the impact stiffness; and $c_{\text {imp }}$ is the pounding damping. The parameters $k_{\text {imp }}$ and $c_{\text {imp }}$ can be obtained from (6)-(9) [29]:

$$
\begin{aligned}
k_{\text {imp }} & =\frac{4}{3 \pi}\left(\frac{1}{\lambda_{1}+\lambda_{2}}\right) \sqrt{\frac{R_{1} R_{2}}{R_{1}+R_{2}}} \\
\lambda_{i} & =\frac{1-v_{i}^{2}}{\pi E_{i}} \quad(i=1,2) \\
R_{i} & =\sqrt[3]{\frac{3 m_{i}}{4 \pi \rho_{i}}} \quad(i=1,2),
\end{aligned}
$$

where $\lambda_{1}$ and $\lambda_{2}$ are the material parameters; $\nu_{i}$ and $E_{i}$ are Poisson's ratio and elastic modulus of the pounding body, respectively; $R_{i}$ is the equivalent radius of the pounding body; and $m_{i}$ and $\rho_{i}$ are the mass and density of the pounding body, respectively.

The pounding occurs on the left:

$$
c_{\text {imp }}=2 \xi_{\text {imp }} \sqrt{k_{\text {imp }} \sqrt{\left(-u_{b}-g_{p}\right)}\left(m_{c}+m_{i}+m_{0}+m\right)} .
$$

The pounding occurs on the right:

$$
c_{\mathrm{imp}}=2 \xi_{\mathrm{imp}} \sqrt{k_{\mathrm{imp}} \sqrt{\left(u_{b}-g_{p}\right)}\left(m_{c}+m_{i}+m_{0}+m\right)} \text {, }
$$

where $\xi_{\text {imp }}$ is the impact damping ratio, which can be expressed as a function of the coefficient of restitution (COR) [33]

$$
\xi_{\text {imp }}=\frac{9 \sqrt{5}}{2} \frac{1-\mathrm{COR}^{2}}{\operatorname{COR}(\operatorname{COR}(9 \pi-16)+16)} .
$$




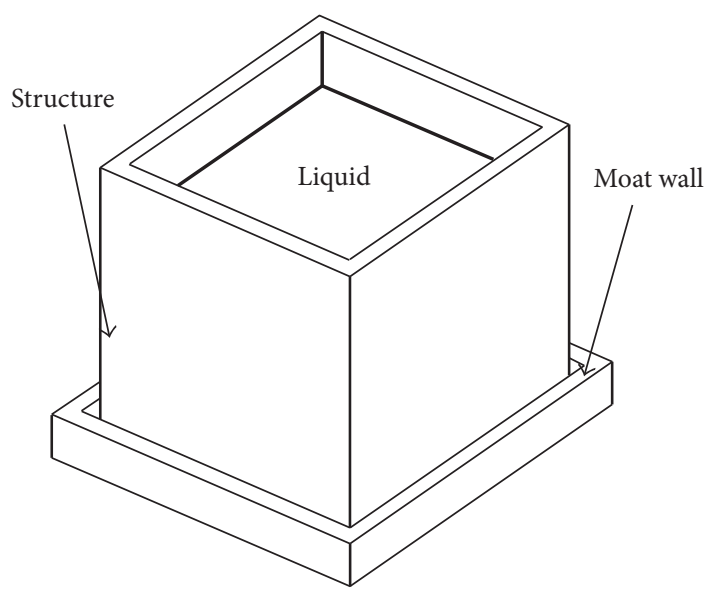

FIGURE 2: Sliding base-isolated concrete rectangular liquid-storage structure with moat wall.

After two objects collide with each other, the reasonable COR greatly influences the rationality of the model. For most pounding problems of engineering structures, the range of CORs is $0.5-0.75$ [31].

\subsection{Simplified Model of a Sliding Isolation Rectangular Liquid-} Storage Structure considering the SSI and Pounding. When the sliding base-isolated liquid-storage structure with moat wall (Figure 2) experiences a large earthquake and its magnitude of slippage exceeds the initial gap, the structure will collide with the moat wall. To study the influence of pounding on the dynamic responses of the liquid-storage structure, a reasonable calculation model should be developed. Currently, the spring-mass model is generally used as a simplification of the liquid-storage structure, and the structural dynamic responses are generally calculated accurately [34]. In this paper, the liquid is represented using a two-particle model [35]. The liquid is divided into 2 parts: rigid mass $m_{0}$ and convective mass $m_{c}$. In addition, the mass of the reinforced concrete structure $m$ is large, so $m$ should also be considered in the dynamic analysis. Because of the assumption that $m_{0}$ moves with the liquid-storage structure, we can add $m$ and $m_{0}$ to obtain the total rigid mass $m+m_{0}$ to simplify the model and reduce the degrees of freedom, and the equivalent heights of the two particles are $h_{c}$ and $h_{0}$, respectively. The convective mass $m_{c}$ is connected to the wall by an equivalent spring with corresponding stiffness and damping of $k_{c}$ and $c_{c}$, respectively; the stiffness and damping of the isolation layer are $k_{0}$ and $c_{0}$, respectively. The lumped parameter model, which is based on the theory of a homogeneous, isotropic, and elastic half space, is used for the massless foundation, and the foundation effect is simulated using a $2 \mathrm{D}$ viscoelastic artificial boundary. The horizontal impedance values of the foundation are $k_{h}$ and $c_{h}$, and the rocking impedance values of the foundation are $k_{\varphi}$ and $c_{\varphi}$.

It is assumed that the liquid-storage structure may collide with both sides of the moat wall during the action of a horizontal earthquake, and the Hertz-damp model is used to simulate the nonlinear pounding problem. The simplified mechanical model of the sliding base-isolated rectangular liquid-storage structure considering the SSI and pounding is shown in Figure 3.

The foundation parameters of the simplified model can be obtained by (1), and the other system parameters can be obtained by using [36]

$$
\begin{aligned}
& m_{c}=0.264\left(\frac{l}{h_{w}}\right) \tanh \left[3.16\left(\frac{h_{w}}{l}\right)\right] M_{L}, \\
& m_{0}=\frac{\tanh \left[0.866\left(l / h_{w}\right)\right]}{0.866\left(l / h_{w}\right)} M_{L}, \\
& h_{c}=\left\{1-\frac{\cosh \left[3.16\left(h_{w} / l\right)-1\right]}{3.16\left(h_{w} / l\right) \sinh \left[3.16\left(h_{w} / l\right)\right]}\right\} h_{w}, \\
& h_{0}=\left[0.5-0.09375\left(\frac{l}{h_{w}}\right)\right] ; \quad \frac{l}{h_{w}}<1.333, \\
& h_{0}=0.375 ; \quad \frac{l}{h_{w}} \geq 1.333, \\
& k_{0}=\left(\frac{2 \pi}{T_{b}}\right)\left(m_{0}+m\right), \\
& c_{0}=2\left(\frac{2 \pi}{T_{b}}\right) \xi_{0}\left(m_{0}+m\right), \\
& \omega_{c}=\sqrt{\frac{g n \pi}{l} \tanh \left(\frac{n \pi h_{w}}{l}\right)} \\
& k_{c}=\omega_{c}^{2} m_{c}, \\
& c_{c}=2 \xi_{c} \sqrt{k_{c} m_{c}},
\end{aligned}
$$

where $l$ is length of the liquid-storage structure, which is parallel to the direction of the earthquake action; $h_{w}$ is the liquid height; $M_{L}$ is the total mass of the liquid; $T_{b}$ is the isolation period; $g$ is the acceleration of gravity; and $\omega_{c}$ is circular frequency of liquid sloshing.

2.4. Dynamic Equation. The dynamic equation of the system shown in Figure 3 can be obtained using the Hamilton principle:

$$
\delta \int_{t_{1}}^{t_{2}}(T-V) d t+\int_{t_{1}}^{t_{2}} \delta W_{n c} d t=0
$$

where $T$ and $V$ are the kinetic energy and potential energy of the system, respectively, and $W_{n c}$ is the total energy dissipated by damping, friction, and pounding.

As seen from Figure 3,

$$
\begin{aligned}
T= & \frac{1}{2} m_{c}\left(\dot{u}_{g}+\dot{u}_{f}+\dot{u}_{0}+\dot{u}_{c}+h_{c} \dot{\varphi}\right)^{2} \\
& +\frac{1}{2}\left(m_{0}+m\right)\left(\dot{u}_{g}+\dot{u}_{f}+\dot{u}_{0}+h_{0} \dot{\varphi}\right)^{2} \\
& +\frac{1}{2} I_{0}(\dot{\varphi})^{2},
\end{aligned}
$$




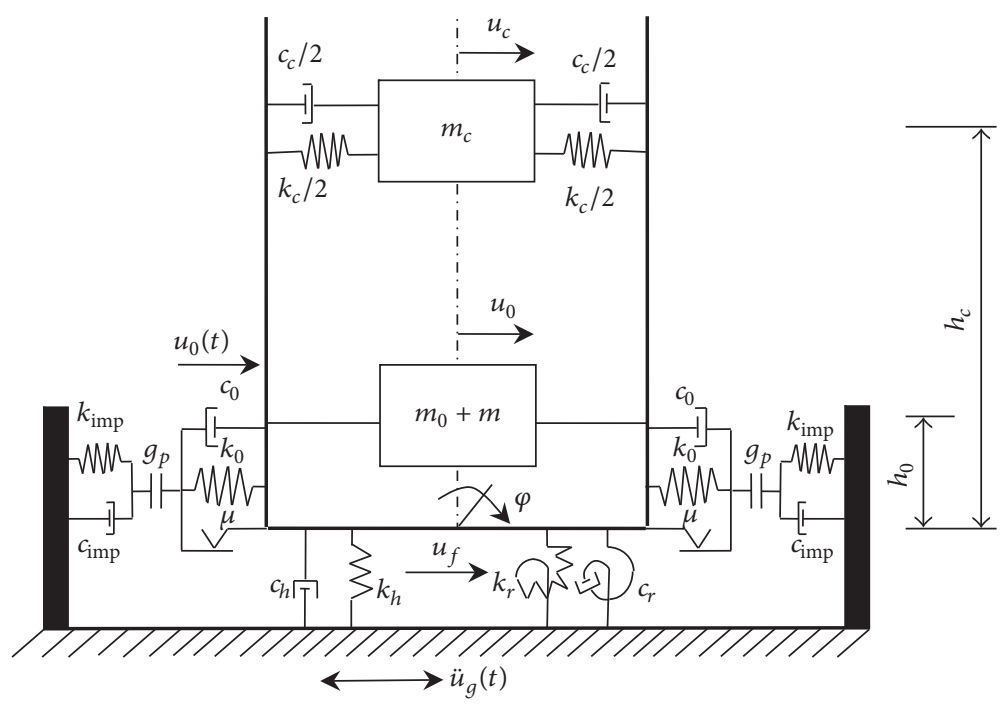

FIGURE 3: Simplified model of a sliding isolation rectangular liquid-storage structure that considers the SSI and pounding.

$$
\begin{aligned}
V= & \frac{1}{2} k_{c} u_{c}^{2}+\frac{1}{2} k_{0} u_{0}^{2}+\frac{1}{2} k_{h} u_{f}^{2}+\frac{1}{2} k_{\varphi} \varphi^{2}, \\
\delta W_{n c}= & -c_{c} \dot{u}_{c} \delta u_{c}-c_{0} \dot{u}_{0} \delta u_{0}-c_{h} \dot{u}_{f} \delta u_{f}-c_{\varphi} \dot{\varphi} \delta \varphi \\
& -F_{f} \delta u_{0}-F_{p} \delta u_{0},
\end{aligned}
$$

where $u_{f}$ and $\varphi$ are the horizontal displacement and rotation angle of foundation, respectively; $I_{0}$ is the structural moment of inertia for rotation around the central axis; $\dot{u}_{g}, \dot{u}_{f}, \dot{u}_{0}$, and $\dot{u}_{c}$ are the velocity of the earthquake, foundation, rigid mass, and liquid convective mass, respectively; $\dot{\varphi}$ is the rotation velocity of the foundation; $h_{c}$ and $h_{0}$ are the heights of the center of gravity that correspond to the liquid convective mass and rigid mass, respectively; $u_{f}, u_{0}$, and $u_{c}$ are the displacements of the foundation, rigid mass, and liquid convective mass, respectively; $\varphi$ is the rotational displacement of the foundation; $F_{f}$ is the friction force, and $F_{f}=-\mu\left(M_{L}+\right.$ $m) g \operatorname{sign}\left(\dot{u}_{0}\right) ; \mu$ is the friction coefficient of the isolation layer; and $\operatorname{sign}\left(\dot{u}_{0}\right)$ is a sign function, when $\dot{u}_{0}$ is greater than zero, the function is equal to -1 , when $\dot{u}_{0}$ is less than zero, it is equal to 1 , and when $\dot{u}_{0}$ is 0 , it is equal to zero.

Inserting (12) into (11), the dynamic equation of the system can be obtained

$$
\mathbf{M U}+\mathbf{C} \dot{\mathbf{U}}+\mathbf{K U}+\mathbf{F}_{f}+\mathbf{F}_{p}=-\mathbf{M}^{\prime} \ddot{u}_{g}
$$

where

M

$$
=\left[\begin{array}{cccc}
m_{c} & 0 & m_{c} & m_{c} h_{c} \\
0 & m+m_{0} & m+m_{0} & 0 \\
m_{c} & m+m_{0} & m_{c}+m+m_{0} & m_{c} h_{c} \\
m_{c} h_{c} & 0 & m_{c} h_{c} & m_{c} h_{c}^{2}+m h_{0}^{2}+m_{0} h_{0}^{2}+I_{0}
\end{array}\right] ;
$$

$\mathbf{C}=\left[\begin{array}{cccc}c_{c} & -c_{c} & 0 & 0 \\ -c_{c} & c_{c}+c_{0} & 0 & 0 \\ 0 & 0 & c_{h} & 0 \\ 0 & 0 & 0 & c_{r}\end{array}\right]$

$\mathbf{K}=\left[\begin{array}{cccc}k_{c} & -k_{c} & 0 & 0 \\ -k_{c} & k_{c}+k_{0} & 0 & 0 \\ 0 & 0 & k_{h} & 0 \\ 0 & 0 & 0 & k_{r}\end{array}\right]$

$\mathbf{M}^{\prime}=\left[\begin{array}{c}m_{c} \\ m+m_{0} \\ m+m_{c}+m_{0} \\ m_{c} h_{c}\end{array}\right]$

$\ddot{\mathbf{U}}=\left\{\begin{array}{l}\ddot{u}_{c} \\ \ddot{u}_{0} \\ \ddot{u}_{f} \\ \ddot{\varphi}\end{array}\right\} ;$

$\dot{\mathbf{U}}=\left\{\begin{array}{c}\dot{u}_{c} \\ \dot{u}_{0} \\ \dot{u}_{f} \\ \dot{\varphi}\end{array}\right\}$

$\mathbf{U}=\left\{\begin{array}{l}u_{c} \\ u_{0} \\ u_{f} \\ \varphi\end{array}\right\} ;$

$\mathbf{F}_{f}=\left\{\begin{array}{c}0 \\ F_{f} \\ 0 \\ 0\end{array}\right\}$; 
TABLE 1: Parameters of the foundation.

\begin{tabular}{lccccc}
\hline $\begin{array}{l}\text { Soil profile } \\
\text { type }\end{array}$ & $\begin{array}{c}\text { Shear wave } \\
\text { velocity } \\
V s(\mathrm{~m} / \mathrm{s})\end{array}$ & $\begin{array}{c}\text { Soil density } \\
\rho\left(\mathrm{kg} / \mathrm{m}^{3}\right)\end{array}$ & $\begin{array}{c}\text { Poisson's } \\
\text { ratio } \\
v\end{array}$ & $\begin{array}{c}\text { Modulus of } \\
\text { elasticity } \\
E(\mathrm{MPa})\end{array}$ & $\begin{array}{c}\text { Damping } \\
\text { ratio } \\
\xi(\%)\end{array}$ \\
\hline Soft soil & 150 & 1900 & 0.30 & 6.12 & 5 \\
\hline
\end{tabular}

$$
\mathbf{F}_{p}=\left\{\begin{array}{c}
0 \\
F_{p} \\
0 \\
0
\end{array}\right\}
$$

The liquid sloshing height is a characteristic dynamic response of liquid-storage structures and should be considered in studies of this type of structures; it can be solved by using [37]

$$
h=0.811 \cdot \frac{l}{2} \cdot\left(\frac{\ddot{u}_{c}+\ddot{u}_{g}}{g}\right) .
$$
(13):

The energy balance equation can be obtained by using

$$
\begin{aligned}
& \int_{0}^{t_{0}} \ddot{\mathbf{U}}^{T} \mathbf{M} \dot{\mathbf{U}} d t+\int_{0}^{t_{0}} \dot{\mathbf{U}}^{T} \mathbf{C} \dot{\mathbf{U}} d t+\int_{0}^{t_{0}} \mathbf{U}^{\mathrm{T}} \mathbf{K} \dot{\mathbf{U}} d t \\
& \quad+\int_{0}^{t_{0}} \mathbf{F}_{f} \dot{\mathbf{U}} d t+\int_{0}^{t_{0}} \mathbf{F}_{p} \dot{\mathbf{U}} d t=-\int_{0}^{t_{0}}\left(\mathbf{M}^{\prime} \ddot{u}_{g}\right)^{T} \dot{\mathbf{U}} d t
\end{aligned}
$$

The earthquake input energy of the system can be obtained by further equivalent conversion of the right side of (16):

$$
\begin{aligned}
E_{I} & =\int_{0}^{t_{0}}\left\{m_{c} \dot{u}_{c}+\left(m+m_{0}\right) \dot{u}_{0}+\left(m+m_{0}+m_{c}\right) \dot{u}_{f}\right. \\
& +m_{c} h_{c} \dot{\varphi} \ddot{u}_{g} d t=\int_{0}^{t_{0}}\left\{m_{c}\left(\dot{u}_{g}+\dot{u}_{f}+\dot{\varphi} h_{c}+\dot{u}_{c}\right)\right. \\
& \left.+\left(m+m_{0}\right)\left(\dot{u}_{0}+\dot{u}_{f}+\dot{u}_{g}\right)-\left(m+m_{0}+m_{c}\right) \dot{u}_{g}\right\} \\
& \cdot \ddot{u}_{g} d t=\int_{0}^{t_{0}}\left\{m_{c}\left(\dot{u}_{g}+\dot{u}_{f}+\dot{\varphi}_{c}+\dot{u}_{c}\right)\right. \\
& \left.+\left(m+m_{0}\right)\left(\dot{u}_{0}+\dot{u}_{f}+\dot{u}_{g}\right)\right\} \ddot{u}_{g} d t-\int_{0}^{t_{0}}\left(m+m_{0}\right. \\
& \left.+m_{c}\right) \dot{u}_{g} \ddot{u}_{g}^{2} d t .
\end{aligned}
$$

For the sliding base-isolated structure, the earthquake input energy is mainly dissipated by damping, friction, and pounding. The energies $E_{D}, E_{F}$, and $E_{P}$ dissipated by damping, friction, and pounding, respectively, can be expressed as

$$
\begin{aligned}
& E_{D}=\int_{0}^{t_{0}} \dot{\mathbf{U}}^{T} \mathbf{C} \dot{\mathbf{U}} d t \\
& E_{F}=\int_{0}^{t_{0}} \mathbf{F}_{f} \dot{\mathbf{U}} d t \\
& E_{P}=\int_{0}^{t_{0}} \mathbf{F}_{p} \dot{\mathbf{U}} d t .
\end{aligned}
$$

\section{Pounding Dynamic Responses}

3.1. Calculation Parameters of the System. The size of the rectangular liquid-storage structure is $6 \mathrm{~m} \times 6 \mathrm{~m} \times 4.8 \mathrm{~m}$, the liquid height is $3.6 \mathrm{~m}$, the wall thickness is $0.2 \mathrm{~m}$, and the moat wall thickness is $0.2 \mathrm{~m}$. The damping ratio $\xi_{0}$ of the structure and the liquid rigid mass is 0.05 . The damping ratio $\xi_{c}$ corresponding to the liquid convection mass is 0.005 . The impact stiffness $k_{p}$ is $2.75 \times 10^{9} \mathrm{~N} / \mathrm{m}$. The impact damping $\xi_{\text {imp }}$ is 0.35 ; the COR is 0.65 [38].

A large number of studies show that a soft soil causes more significant changes to the structural dynamic responses. To study the influence of the foundation effect on the dynamic responses of the sliding base-isolated liquid-storage structure, a soft soil site is assumed to be the foundation based on the Uniform Building Code (UBC2007). The material parameters of this soft soil are shown in Table 1. The dynamic shear modulus $G$ used to consider the foundation effect is assumed to be $60 \%$ of the maximum shear modulus $G_{\max }$. The equivalent radii $r_{h}$ and $r_{r}$ corresponding to foundation translation and rotation are $4 \mathrm{~m}$ [39], and $L$ and $B$ of the foundation are $66 \mathrm{~m}$.

3.2. Seismic Waves. The near-field pulse-like Chi-Chi earthquake and far-field Imperial Valley-06 earthquake are chosen to conduct time history analyses. The seismic waves are from the PEER strong earthquake observation database (http://peer.berkeley.edu/smcat/), and information about the seismic waves is shown in Table 2. To study the dynamic responses of the sliding base-isolated liquid-storage structure, the peak ground acceleration (PGA) of the two seismic waves is adjusted to $1.0 \mathrm{~g}$, and the adjusted acceleration time history curves are shown in Figure 4.

3.3. Effect of the SSI on the Dynamic Responses of a Sliding Isolation Liquid-Storage Structure. The initial gap is $0.10 \mathrm{~m}$, the friction coefficient is 0.06 , and the other parameters are mentioned previously. To study the influences of the SSI on the dynamic responses of a liquid-storage structure, the 
TABLE 2: Seismic waves.

\begin{tabular}{|c|c|c|c|c|c|}
\hline Earthquake & Station & PGA (g) & PGV $(\mathrm{cm} / \mathrm{s})$ & PGD (m) & Pulse duration $T_{p}(\mathrm{~s})$ \\
\hline Chi-Chi & TCU036 & 0.13381 & 11.50826 & 0.02336 & 5.341 \\
\hline $\begin{array}{l}\text { Imperial } \\
\text { Valley-06 }\end{array}$ & $\begin{array}{l}\text { Westmorland } \\
\text { Fire Sta }\end{array}$ & 0.07605 & 4.24472 & 0.00838 & - \\
\hline
\end{tabular}

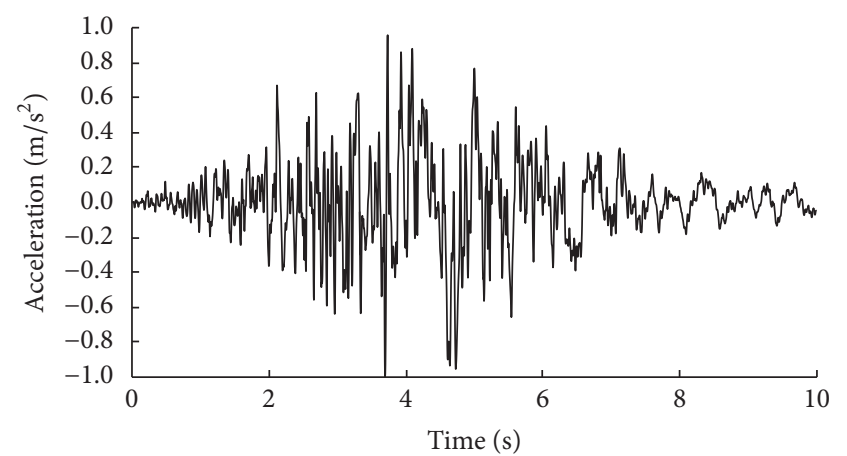

(a) Chi-Chi

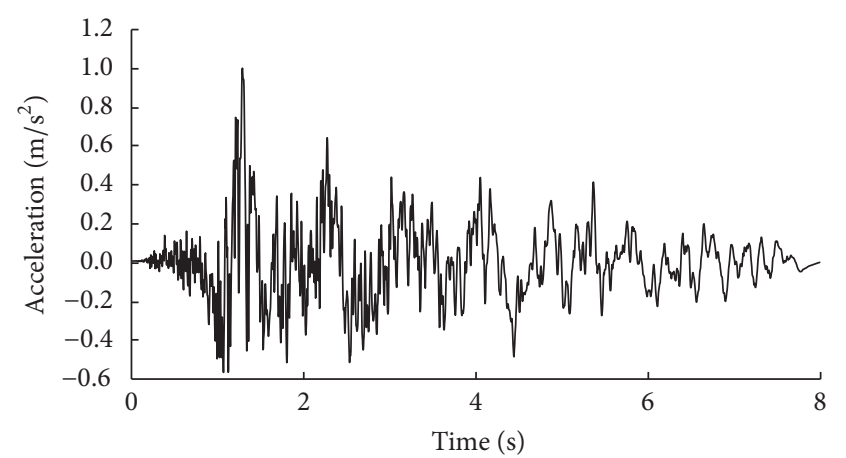

(b) Imperial Valley-06

Figure 4: Seismic waves.

structural dynamic responses are calculated with and without the SSI. The liquid sloshing height, structural acceleration $\ddot{u}_{0}$, impact force, and structural displacement $u_{0}$ for the two conditions are shown in Figure 5.

As shown in Figure 5, the impact force and structural acceleration show the pulse phenomenon at the moment of pounding. The liquid sloshing height increases when the SSI is considered, the probable reason being that the SSI effect extends the period of the isolation system; namely, the periods of the system corresponding to considering the SSI and not considering the SSI are $2.0 \mathrm{~s}$ and $2.3 \mathrm{~s}$; besides, the liquid sloshing period $(2.726 \mathrm{~s})$ is long. Because the difference of structure period and liquid sloshing period becomes small, the liquid sloshing height is increased. The structural acceleration and impact force will be reduced after considering the SSI because the foundation plays the role of a buffer at the moment of pounding. Under the action of strong near-field Chi-Chi and far-field Imperial Valley06 earthquake, the structural slippage will exceed the initial gap but the sliding of the structure is limited because of the action of the surrounding moat wall, so the influence of the SSI effect on the maximum displacement response of the structure is relatively small. In addition to the slippage, the structural dynamic response induced by the near-field earthquake is much larger than the response due to the farfield earthquake. After considering the SSI, the maximum liquid sloshing heights under the action of near-field and farfield earthquakes are $0.822 \mathrm{~m}$ and $0.266 \mathrm{~m}$, respectively, the maximum structural acceleration values are $49.36 \mathrm{~m} / \mathrm{s}^{2}$ and $17.59 \mathrm{~m} / \mathrm{s}^{2}$, respectively, and the maximum impact forces are $7.02 \times 10^{6} \mathrm{~N}$ and $1.70 \times 10^{6} \mathrm{~N}$, respectively. From this analysis, we can conclude that near-field pulse-like Chi-Chi earthquake causes more serious damage to a sliding base-isolated structure than far-field Imperial Valley-06 earthquake and that the former will greatly influence the function of the sliding isolation structure.

3.4. Effect of the SSI on the Energy Responses of a LiquidStorage Structure. A remarkable characteristic of sliding isolation is that the friction effect will consume a large amount of energy when the structure moves. In addition, the damping of the system will dissipate a portion of the energy, and the pounding effect can dissipate another portion of the energy when pounding occurs. In addition, in order to validate the motion equations derived from Hamilton's principle, the input energy of the earthquake and the total dissipated energy considering the SSI effect are shown in Figure 6. For the two types of earthquake actions, the friction energy dissipation $E_{F}$, the pounding energy dissipation $E_{P}$, and the damping energy dissipation $E_{D}$ that consider the SSI or not are shown in Figure 7.

As seen from Figure 6, under the action of Chi-Chi and Imperial Valley-06 earthquakes, the difference of input energy curve and total dissipated energy curve is small when the SSI effect is considered, so the rationality of the corresponding equations proposed in this paper is verified to a certain degree. Besides, it is shown that the earthquake input energy is mainly dissipated by damping, friction, and pounding.

As seen in Figure 7, the friction energy dissipation and the pounding energy dissipation are decreased and the damping energy dissipation is increased when the SSI are considered. $E_{F}$ and $E_{D}$ increase gradually as the time increases, and finally, they tend to be stable. $E_{P}$ only occurs at every pounding moment. For the no pounding state, $E_{P}$ does not increase, and the corresponding curve is linear, so $E_{P}$ has a ladder-type growth phenomenon with time. The friction energy dissipation of the sliding isolation structure is much 


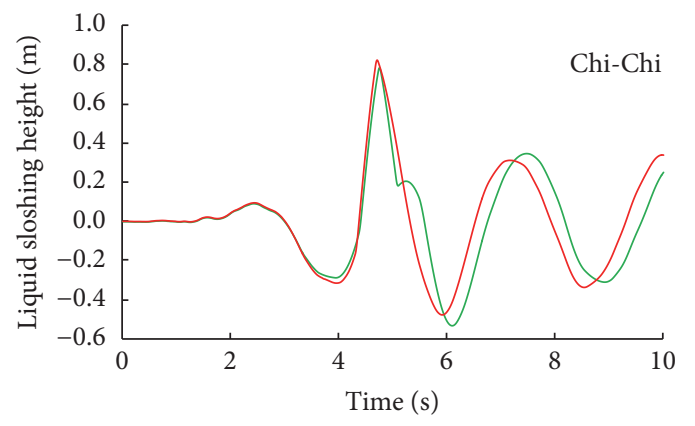

— Without SSI

_ With SSI

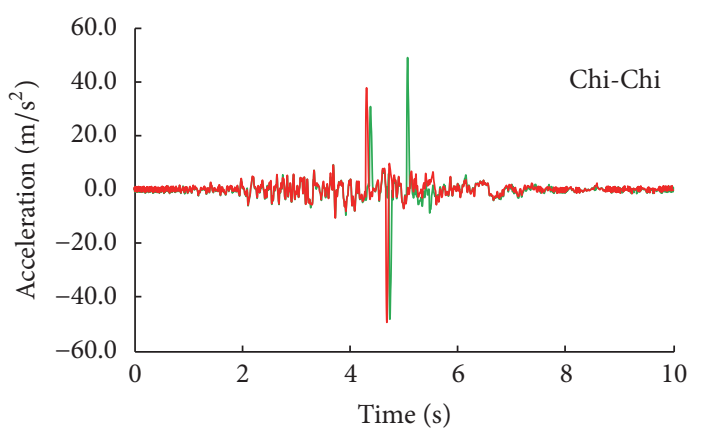

- Without SSI

- With SSI

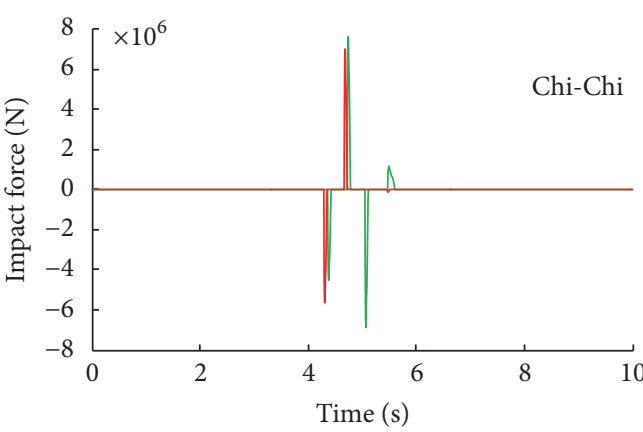

_ Without SSI

— With SSI

(c) Impact force

(a) Liquid sloshing height

(b) Structural acceleration
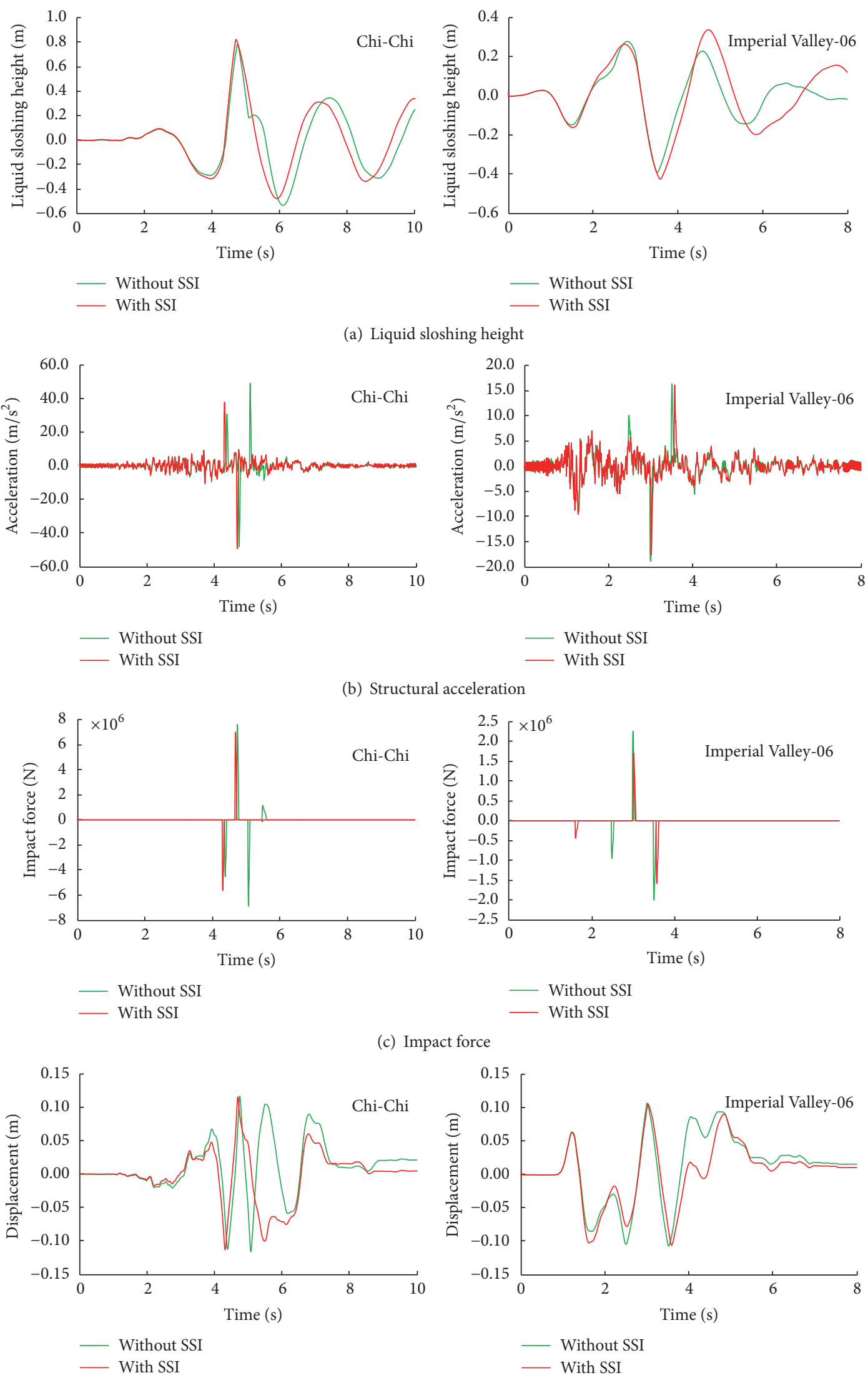

(d) Structural displacement

FIGURE 5: Effect of SSI on structural dynamic responses considering pounding. 

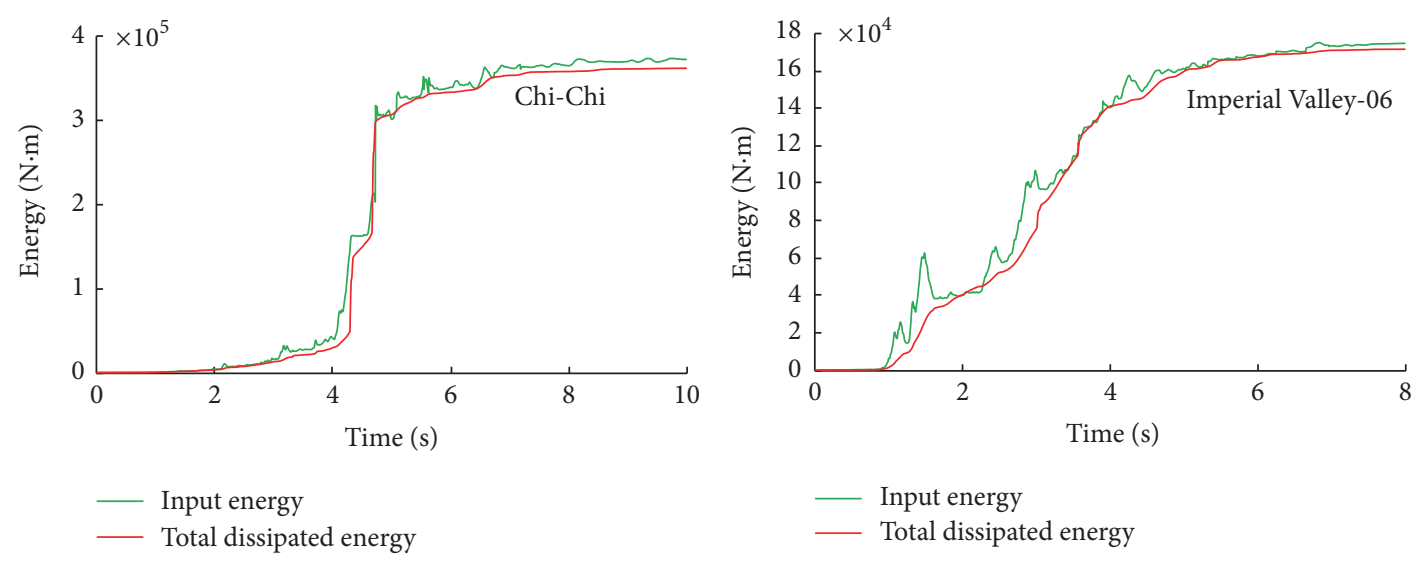

Figure 6: Comparison of input energy and total dissipated energy.

larger than the damping energy dissipation. Therefore, a reasonable selection of the friction coefficient of the sliding isolation layer has an important influence on the design of the sliding isolation structure.

By comparing the corresponding energy responses for the actions of the near-field pulse-like Chi-Chi earthquake and far-field Imperial Valley-06 earthquake, we found that $E_{F}, E_{P}$, and $E_{D}$ corresponding to the Chi-Chi wave are much larger than those of the Imperial Valley-06 wave. To ensure that a sliding base-isolated liquid-storage structure that experiences strong earthquakes can continue to play its important role, the design requirements of each part of the structure should be higher for near-field pulse-like Chi-Chi earthquake because each part of the system needs to dissipate more seismic energy.

\section{Peak Response Analysis}

4.1. Effect of the Initial Gap on Peak Responses. $g_{p}$ is one of the important parameters in the design of base-isolated structures, and the gap size determines the occurrence of pounding and the impact of pounding on the structural dynamic responses. To study the influence of $g_{p}$ on the dynamic responses while considering the SSI of a sliding isolation rectangular liquid-storage structure, different values of $g_{p}$, liquid sloshing height, structural acceleration, and impact force corresponding to different $g_{p}$ are studied. The calculated results are shown in Figure 8.

As shown in Figure $8, g_{p}$ has little effect on the liquid sloshing height after considering the SSI. The maximum liquid sloshing height caused by near-field Chi-Chi earthquake is approximately 2-3 times the height of the far-field Imperial Valley-06 earthquake for a given value of $g_{p}$. In addition to some individual $g_{p}$, the response of the impact force and structural acceleration caused by the near-field Chi-Chi earthquake is much larger than the far-field Imperial Valley06 earthquake overall, and the impact force and structural acceleration first increase and then decrease as $g_{p}$ increases. For the Chi-Chi and Imperial Valley-06 waves, the structural acceleration and impact forces are maximum values when $g_{p}$ is $0.04 \mathrm{~m}$ and $0.18 \mathrm{~m}$, respectively. Therefore, in the design of a sliding isolation structure, there is critical $g_{p}$ that will cause the maximum dynamic responses when the pounding occurs, which makes the structure more susceptible to damage and seriously affects the effectiveness of the isolation structure. Moreover, $g_{p}$ corresponding to near-field Chi-Chi earthquake and far-field Imperial Valley-06 earthquake that have more adverse effects on the structure is different. In the design of this type of structure, to select a reasonable gap to minimize the adverse effect of pounding on the system, the site conditions should be seriously considered.

4.2. Effect of the Friction Coefficient on the Peak Responses. Friction coefficient $\mu$ is an important design parameter of a sliding isolation structure because it directly determines the shock absorption effect of this type of structure. For the case that considers the foundation effect, studying the influence of $\mu$ on the dynamic responses is helpful to understand the pounding of the sliding isolation structure and to provide a theoretical basis for a rational design of a sliding isolation structure. After the SSI is considered, the liquid sloshing height, structural acceleration, and impact force corresponding to different friction coefficients are shown in Figure 9.

As seen in Figure 9, the friction coefficient has little effect on the liquid sloshing wave height for the case of pounding that considers the SSI. In addition to the friction coefficients of 0.08 and 0.10 , the impact force and structural acceleration decrease as the friction coefficient increases overall. In comparison, based on fitted curve, we obtained the influence of the friction coefficient on the dynamic response of the structure for the near-field Chi-Chi earthquake is less than the far-field Imperial Valley-06 earthquake. However, under different friction coefficients, the dynamic responses of the system for the near-field Chi-Chi earthquake are significantly greater than the far-field Imperial Valley-06 earthquake. The larger coefficient of friction can reduce the probability of pounding and the structural dynamic responses in the case of pounding. However, it should be noted that the effect of this type of base-isolated structure is achieved by sliding. When the friction coefficient is too large, the structure will not slip under some smaller earthquakes, which is similar to the structure with a fixed support, so that the damping effect 


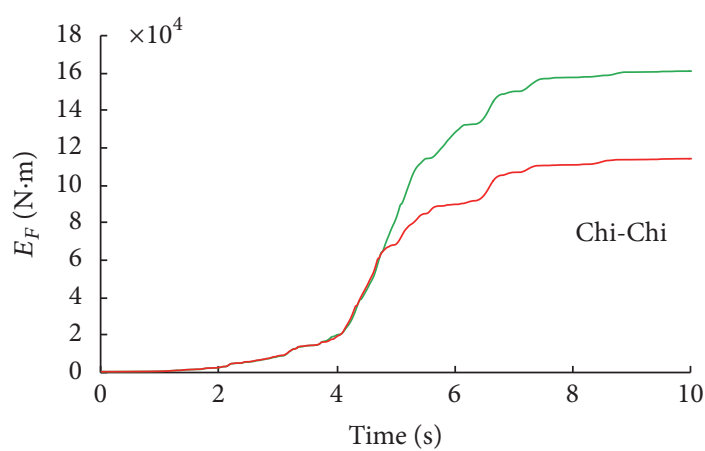

- Without SSI With SSI

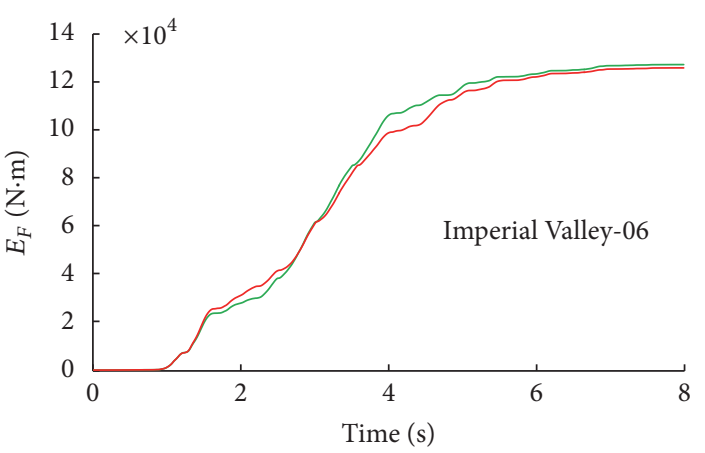

Without SSI With SSI

(a) Friction energy dissipation $E_{F}$

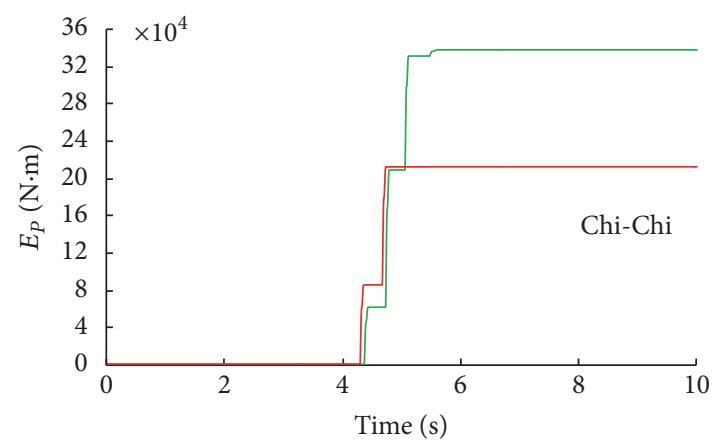

Without SSI — With SSI

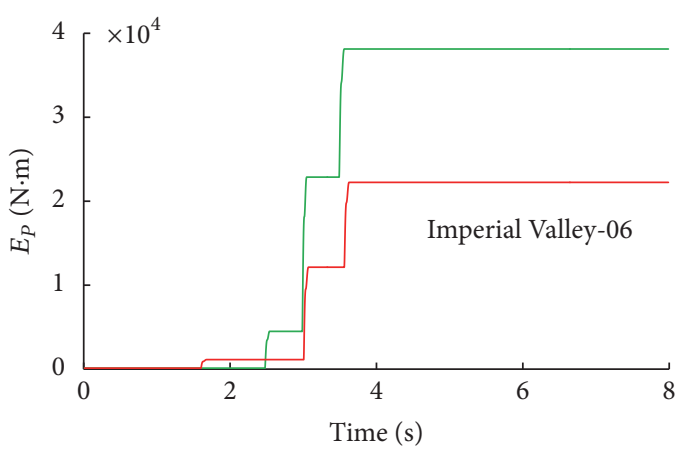

- Without SSI

(b) Pounding energy dissipation $E_{P}$

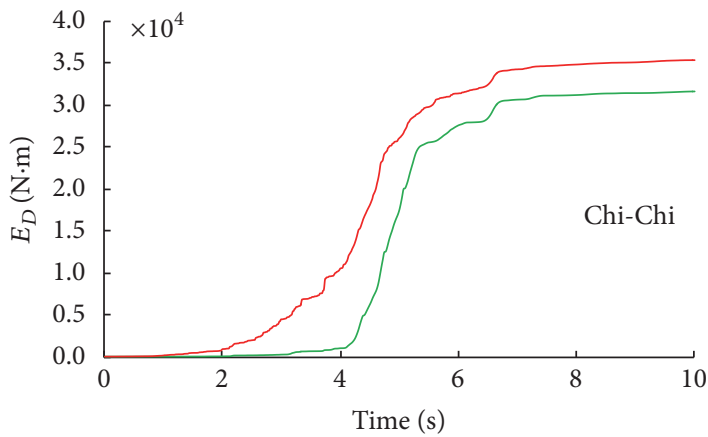

Without SSI With SSI

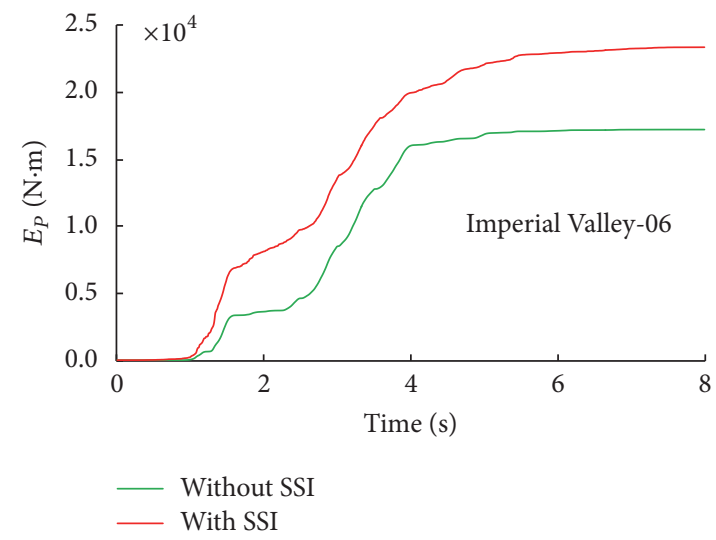

(c) Damping energy dissipation $E_{D}$

FIGURE 7: Effects of SSI on energy dissipation.

of the sliding isolation structure will be lost. Therefore, after comprehensive consideration, the friction coefficient should be an intermediate value to better balance the needs of all parties.

4.3. Correlation of the Friction Coefficient and Initial Gap on the Maximum Horizontal Displacement of the Structure. Slippage is an important characteristic dynamic response of a sliding isolation structure. Although the amount of slippage has little effect on the liquid-storage structure in theory, when taking into account some practical problems, especially liquid-storage structures in the petroleum chemical industry and nuclear industry, once the slippage exceeds a critical limit, the accessory pipelines will be damaged, and liquid may leak out. This result is as serious as failure of the structure itself. If we ignore the problem, the loss of a sliding isolation structure will outweigh the gain. To have a more comprehensive understanding of the slippage of the sliding isolation structure, the correlation effect of the friction coefficient and initial gap on the maximum horizontal displacement of a 


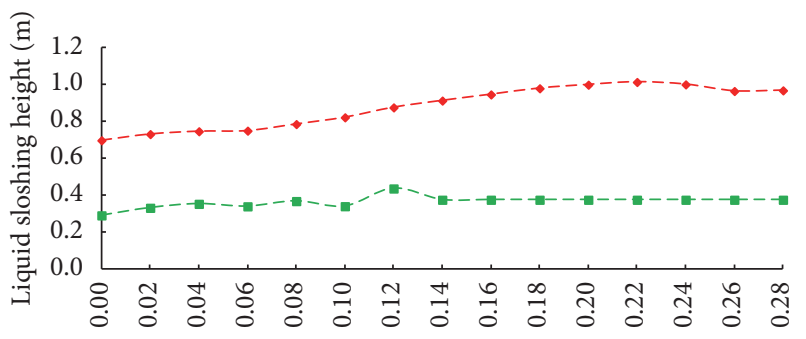

$g_{p}(\mathrm{~m})$

- - Chi-Chi

- - - Imperial Valley-06

(a) Liquid sloshing height

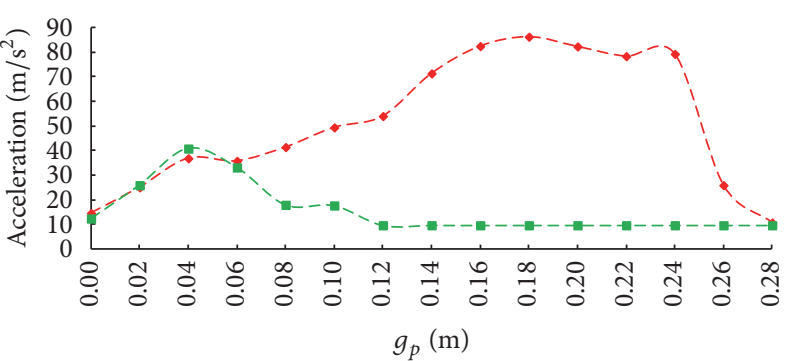

- Chi-Chi

- - Imperial Valley-06

(b) Structural acceleration

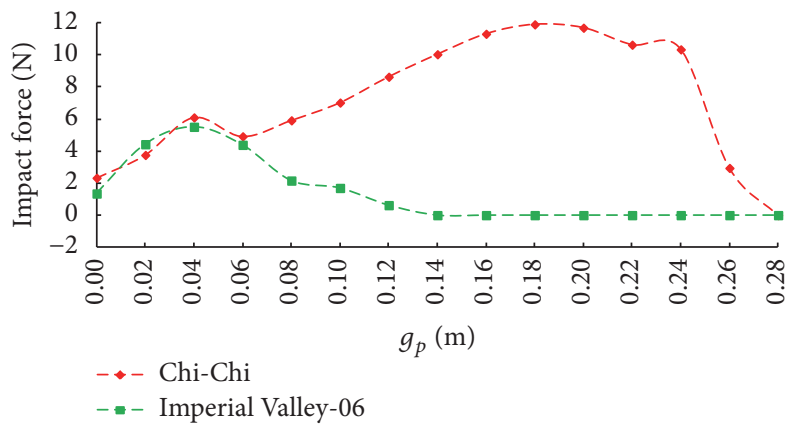

(c) Impact force

Figure 8: Pounding dynamic responses corresponding to different gap sizes.

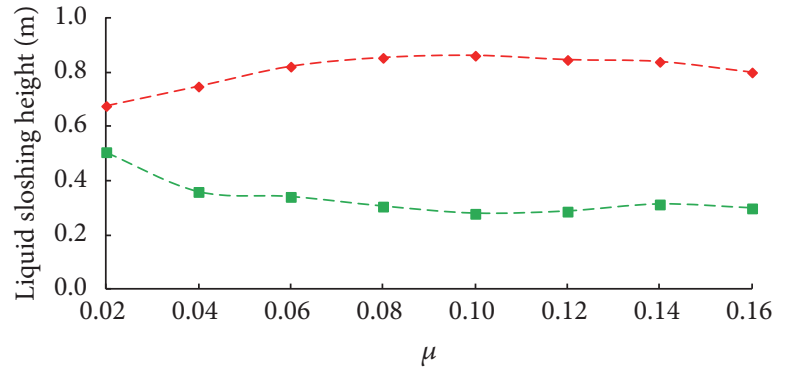

$-\bullet$ Chi-Chi

- Imperial Valley-06

(a) Liquid sloshing height

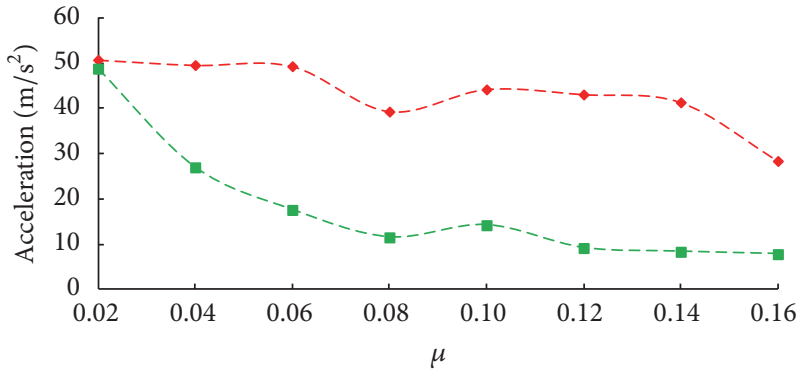

-- Chi-Chi

- Imperial Valley-06

(b) Structural acceleration

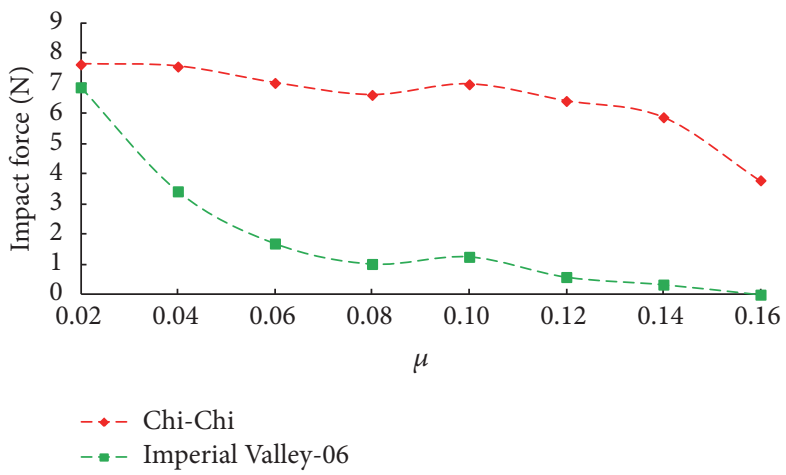

(c) Impact force

FIGURE 9: Pounding dynamic responses corresponding to different friction coefficients. 


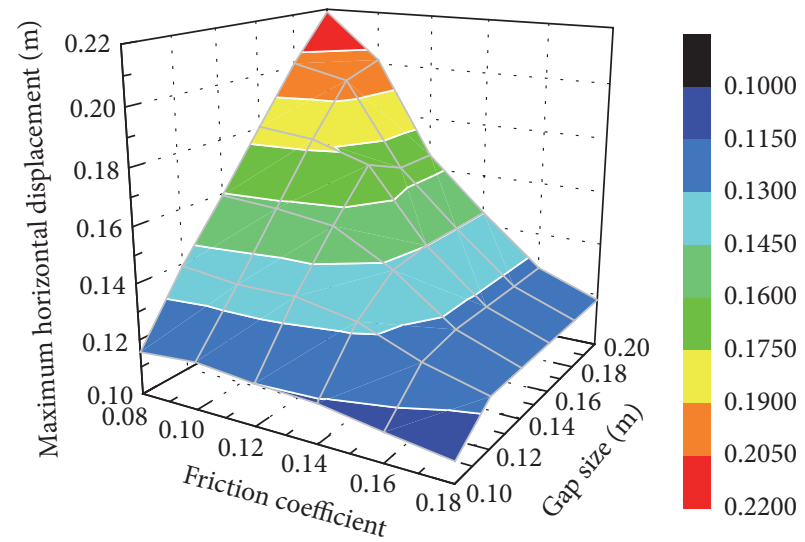

(a) Chi-Chi earthquake

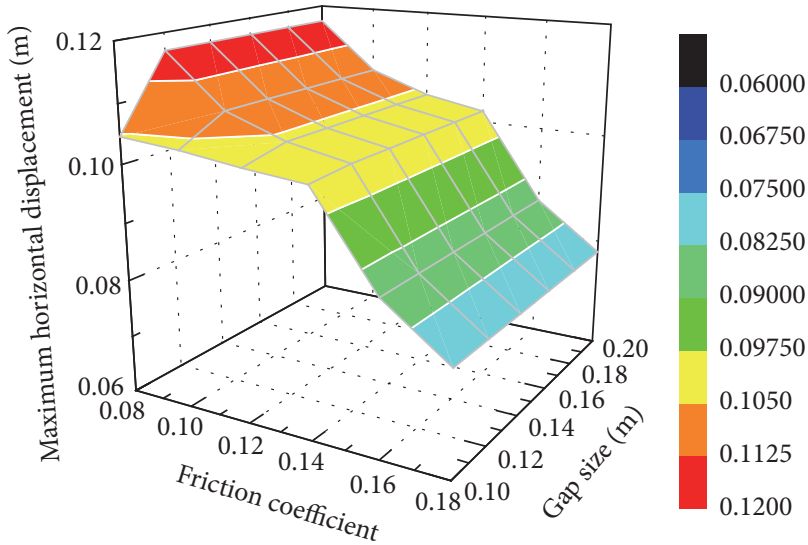

(b) Imperial Valley-06 earthquake

FIGURE 10: Correlation effects of the friction coefficient and initial gap on the maximum horizontal displacement of the structure.

liquid-storage structure is studied considering the SSI. The calculated results are shown in Figure 10.

As seen in Figure 10, the maximum horizontal displacement of the liquid-storage structure decreases as the friction coefficient increases and increases as the initial gap increases overall. Under the near-field Chi-Chi earthquake, when the initial gap $g_{p}$ is small $(0.10 \mathrm{~m}$ and $0.12 \mathrm{~m})$, the friction coefficient has little effect on the maximum slippage of the liquid-storage structure because the maximum horizontal displacement of the liquid-storage structure with different friction coefficients can all reach $g_{p}$. As $g_{p}$ increases, the effect of the friction coefficient on the slippage becomes obvious. In particular, when $g_{p}$ is greater than or equal to 0.20 , as the friction coefficient increases, the decreasing trend of slippage is even more significant. When the friction coefficient is large, the slippage is small, so $g_{p}$ has little effect on the slippage. For the far-field Imperial Valley-06 earthquake, when the friction coefficient is small (such as 0.08 or 0.10 ), the slippage increases with increase of $g_{p}$. When the friction coefficient is greater than or equal to 0.12 , the structure will not collide with the moat wall, so $g_{p}$ has no effect on the slippage.

Based on the calculated results of Figure 10, if there is no surrounding moat wall, the maximum slippage will be greater than $0.20 \mathrm{~m}$ for the near-field Chi-Chi earthquake and the maximum slippage will be smaller than $0.12 \mathrm{~m}$ for the far-field Imperial Valley-06 earthquake. Therefore, the amount of slippage for the structure experiencing near-field Chi-Chi earthquake is significantly greater than the far-field Imperial Valley-06 earthquake. To avoid damage caused by large amounts of slippage to accessory pipelines of a sliding liquid-storage structure in the petroleum chemical industry, a study of limiting measures for near-field pulse-like earthquakes should receive great attention. Meanwhile, for nearfield pulse-like Chi-Chi earthquake, it is more necessary to study mitigation measures to reduce the pounding dynamic responses.

\section{Conclusions}

The SSI and the pounding possibility between a sliding isolation liquid-storage structure and its moat wall are considered in this paper. A simplified mechanical model of the sliding base-isolated liquid-storage structure is established, and the pounding dynamic responses of the system under the action near-field Chi-Chi earthquake and far-field Imperial Valley06 earthquake are studied. The effects of the SSI, initial gap, and friction coefficient on the dynamic responses of a liquidstorage structure are discussed. The main conclusions are as follows:

(1) The liquid sloshing height of a sliding isolation liquidstorage structure increases when the SSI is considered because the SSI increases the period of the isolation structure and the difference between the isolation period and liquid sloshing period becomes small. When the liquid-storage structure collides with the moat wall, the structural dynamic responses due to a pulse phenomenon will appear, but the structural acceleration and impact force are reduced because of the buffer effect of the foundation.

(2) The friction energy dissipation and pounding energy dissipation of the system are reduced when the SSI is considered. The friction energy dissipation and damping energy dissipation gradually increase as the time increases, whereas the pounding energy dissipation is only affected by each pounding and shows a ladder-type growth phenomenon as the time increases. The friction energy dissipation, pounding energy dissipation, and damping energy dissipation for near-field pulse-like Chi-Chi earthquake are far greater than far-field Imperial Valley-06 earthquake. To ensure that the structure continues to work properly under some strong earthquakes, the nearfield pulse-like Chi-Chi earthquake affects the design process more for each part of the structure.

(3) After considering the SSI, the dynamic responses of a sliding isolation liquid-storage structure with different initial gaps for near-field Chi-Chi earthquake are generally larger than far-field Imperial Valley-06 earthquake. $g_{p}$ has little effect on the liquid sloshing height, but the structural acceleration and impact 
force first increase and then decrease as $g_{p}$ increases. Therefore, when designing a sliding isolation structure, it should be noted that a certain value of $g_{p}$ will result in the maximum pounding dynamic responses and the effectiveness of the isolation structure will be seriously affected.

(4) Increasing the friction coefficient can reduce the pounding dynamic responses of the structure to a certain extent. However, when the friction coefficient is large, this type of isolation structure will not slide, so it will lose the designed shock absorption during some earthquakes. Therefore, the selection of the friction coefficient of a sliding isolation structure should be considered comprehensively and an intermediate value for the friction coefficient is ideal.

(5) When the friction coefficient is small, the initial gap greatly affects the slippage of a sliding isolation liquidstorage structure. When the initial gap is large, the friction coefficient greatly affects the slippage of the sliding isolation liquid-storage structure.

\section{Competing Interests}

The authors declare that there is no conflict of interests regarding the publication of this paper.

\section{Acknowledgments}

This paper is supported in part by the National Natural Science Foundation of China (Grant nos. 51368039 and 51478212), the Education Ministry Doctoral Tutor Foundation of China (Grant no. 20136201110003), and the Plan Project of Science and Technology in Gansu Province (Grant no. 144GKCA032).

\section{References}

[1] M. R. Shekari, N. Khaji, and M. T. Ahmadi, "A coupled BEFE study for evaluation of seismically isolated cylindrical liquid storage tanks considering fluid-structure interaction," Journal of Fluids \& Structures, vol. 25, no. 3, pp. 567-585, 2009.

[2] H. Vosoughifar and M. Naderi, "Numerical analysis of the baseisolated rectangular storage tanks under bi-directional seismic excitation," British Journal of Mathematics \& Computer Science, vol. 4, no. 21, pp. 3054-3067, 2014.

[3] X. Cheng, L. Cao, and H. Zhu, "Liquid-solid interaction seismic response of an isolated overground rectangular reinforcedconcrete liquid-storage structure," Journal of Asian Architecture and Building Engineering, vol. 14, no. 1, pp. 175-180, 2015.

[4] X. S. Cheng, L. Zhao, Y. R. Zhao, and A. J. Zhang, "FSI resonance response of liquid-storage structures made of rubberisolated rectangular reinforced concrete," Electronic Journal of Geotechnical Engineering, vol. 20, no. 7, pp. 1809-1824, 2015.

[5] E. Abali and E. Uçkan, "Parametric analysis of liquid storage tanks base isolated by curved surface sliding bearings," Soil Dynamics \& Earthquake Engineering, vol. 30, no. 1-2, pp. 21-31, 2010.

[6] R. Zhang, D. Weng, and X. Ren, "Seismic analysis of a LNG storage tank isolated by a multiple friction pendulum system,"
Earthquake Engineering and Engineering Vibration, vol. 10, no. 2, pp. 253-262, 2011.

[7] V. R. Panchal and R. S. Jangid, "Seismic response of liquid storage steel tanks with variable frequency pendulum isolator," KSCE Journal of Civil Engineering, vol. 15, no. 6, pp. 1041-1055, 2011.

[8] M. K. Shrimali and R. S. Jangid, "A comparative study of performance of various isolation systems for liquid storage tanks," International Journal of Structural Stability \& Dynamics, vol. 2, no. 4, pp. 573-591, 2002.

[9] A. A. Seleemah and M. El-Sharkawy, "Seismic response of base isolated liquid storage ground tanks," Ain Shams Engineering Journal, vol. 2, no. 1, pp. 33-42, 2011.

[10] J. Liu, S. Wang, Y. Shi, and X. Cao, "Shaking table test for isolated structures supported on slide-limited innovative separated friction sliding device," Xian Jianzhu Keji Daxue Xuebao/Journal of Xian University of Architecture and Technology, vol. 47, no. 4, pp. 498-502, 2015.

[11] S. Nagarajaiah and X. Sun, "Base-isolated FCC building: impact response in Northridge earthquake," Journal of Structural Engineering, vol. 127, no. 9, pp. 1063-1075, 2001.

[12] V. A. Matsagar and R. S. Jangid, "Seismic response of baseisolated structures during impact with adjacent structures," Engineering Structures, vol. 25, no. 10, pp. 1311-1323, 2003.

[13] P. Komodromos, "Simulation of the earthquake-induced pounding of seismically isolated buildings," Computers and Structures, vol. 86, no. 7-8, pp. 618-626, 2008.

[14] R. Fu, K. Ye, and L. Li, "Seismic response of LRB baseisolated structures under near-fault pulse-like ground motions considering potential pounding," Engineering Mechanics, vol. 27, no. 2, pp. 298-302, 2010.

[15] A. Masroor and G. Mosqueda, "Impact model for simulation of base isolated buildings impacting flexible moat walls," Earthquake Engineering \& Structural Dynamics, vol. 42, no. 3, pp. 357376, 2013.

[16] D. R. Pant and A. C. Wijeyewickrema, "Performance of base-isolated reinforced concrete buildings under bidirectional seismic excitation considering pounding with retaining walls including friction effects," Earthquake Engineering and Structural Dynamics, vol. 43, no. 10, pp. 1521-1541, 2014.

[17] J. Fan, X.-H. Long, and J. Zhao, "Caculation on robust fragility curves of base-isolated structure under near-fault earthquake considering base pounding," Engineering Mechanics, vol. 31, no. 1, pp. 166-172, 2014.

[18] S. Khatiwada and N. Chouw, "Limitations in simulation of building pounding in earthquakes," International Journal of Protective Structures, vol. 5, no. 2, pp. 123-150, 2014.

[19] W. Q. Liu, C.-P. Li, S. G. Wang, D. S. Du, and H. Wang, "Comparative study on high-rise isolated structure founded on various soil foundations by using shaking table tests," Zhendong yu Chongji/Journal of Vibration and Shock, vol. 32, no. 16, pp. 128-151, 2013.

[20] Z. Haiyang, Y. Xu, Z. Chao, and J. Dandan, "Shaking table tests for the seismic response of a base-isolated structure with the SSI effect," Soil Dynamics \& Earthquake Engineering, vol. 67, pp. 208-218, 2014.

[21] A. Krishnamoorthy and S. Anita, "Soil-structure interaction analysis of a FPS-isolated structure using finite element model," Structures, vol. 5, pp. 44-57, 2016.

[22] T. Karabork, I. O. Deneme, and R. P. Bilgehan, "A comparison of the effect of SSI on base isolation systems and fixed-base 
structures for soft soil," Geomechanics and Engineering, vol. 7, no. 1, pp. 87-103, 2014.

[23] P. Komodromos, P. C. Polycarpou, L. Papaloizou, and M. C. Phocas, "Response of seismically isolated buildings considering poundings," Earthquake Engineering \& Structural Dynamics, vol. 36, no. 12, pp. 1605-1622, 2007.

[24] K. T. Chau, X. X. Wei, X. Guo, and C. Y. Shen, "Experimental and theoretical simulations of seismic poundings between two adjacent structures," Earthquake Engineering \& Structural Dynamics, vol. 32, no. 4, pp. 537-554, 2003.

[25] S. Mahmoud and S. A. Gutub, "Earthquake induced poundinginvolved response of base-isolated buildings incorporating soil flexibility," Advances in Structural Engineering, vol. 16, no. 12, 2013.

[26] K. Shakya and A. C. Wijeyewickrema, "Mid-column pounding of multi-story reinforced concrete buildings considering soil effects," Advances in Structural Engineering, vol. 12, no. 1, pp. 7185, 2009.

[27] R. V. Whitman and F. E. Richart, "Design procedures for dynamically loaded foundations," Journal of Soil Mechanics \& Foundations Division ASCE, vol. 92, no. 6, pp. 169-193, 1967.

[28] S. Mahmoud, A. Abd-Elhamed, and R. Jankowski, "Earthquake-induced pounding between equal height multi-storey buildings considering soil-structure interaction," Bulletin of Earthquake Engineering, vol. 11, no. 4, pp. 1021-1048, 2013.

[29] S. Muthukumar and R. Desroches, "Evaluation of impact models for seismic pounding," in Proceedings of the 13th World Conference on Earthquake Engineering, Vancouver, Canada, 2004.

[30] S. Mahmoud and R. Jankowski, "Modified linear viscoelastic model of earthquake-induced structural pounding," Iranian Journal of Science \& Technology, Transaction B: Engineering, vol. 35, no. 1, pp. 51-62, 2011.

[31] R. Jankowski, "Non-linear viscoelastic modelling of earthquake-induced structural pounding," Earthquake Engineering and Structural Dynamics, vol. 34, no. 6, pp. 595-611, 2005.

[32] W. Goldsmith, Impact: The Theory and Physical Behavior of Colliding Solids, Edward Arnold, London, UK, 1st edition, 1960.

[33] R. Jankowski, "Analytical expression between the impact damping ratio and the coefficient of restitution in the non-linear viscoelastic model of structural pounding," Earthquake Engineering and Structural Dynamics, vol. 35, no. 4, pp. 517-524, 2006.

[34] Q. Z. Ge, D. G. Weng, and R. F. Zhang, "A nonlinear simplified model of liquid storage tank and primary resonance analysis," Gongcheng Lixue/Engineering Mechanics, vol. 31, no. 5, pp. 166202, 2014.

[35] G. W. Housner, "The dynamic behavior of water tanks," Bulletin of the Seismological Society of America, vol. 53, no. 2, pp. 381-387, 1963.

[36] ACI Committee 350, "Seismic design of liquid-containing concrete structures (ACI 350.3-01) and commentary (ACI 350.3R01)," American Concrete Institute, Farmington Hills, Miss, USA, 2001.

[37] K. Ikago, K. Saito, and N. Inoue, "Seismic control of singledegree-of-freedom structure using tuned viscous mass damper," Earthquake Engineering \& Structural Dynamics, vol. 41, no. 3, pp. 453-474, 2012.

[38] R. Jankowski, "Earthquake-induced pounding between equal height buildings with substantially different dynamic properties," Engineering Structures, vol. 30, no. 10, pp. 2818-2829, 2008.
[39] I. Takewaki, "Bound of earthquake input energy to soilstructure interaction systems," Soil Dynamics \& Earthquake Engineering, vol. 25, no. 7-10, pp. 741-752, 2005. 


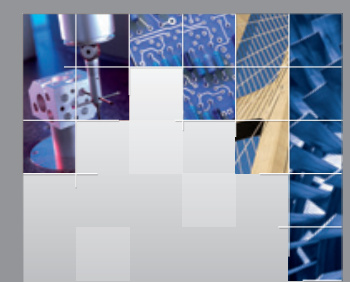

\section{Enfincering}
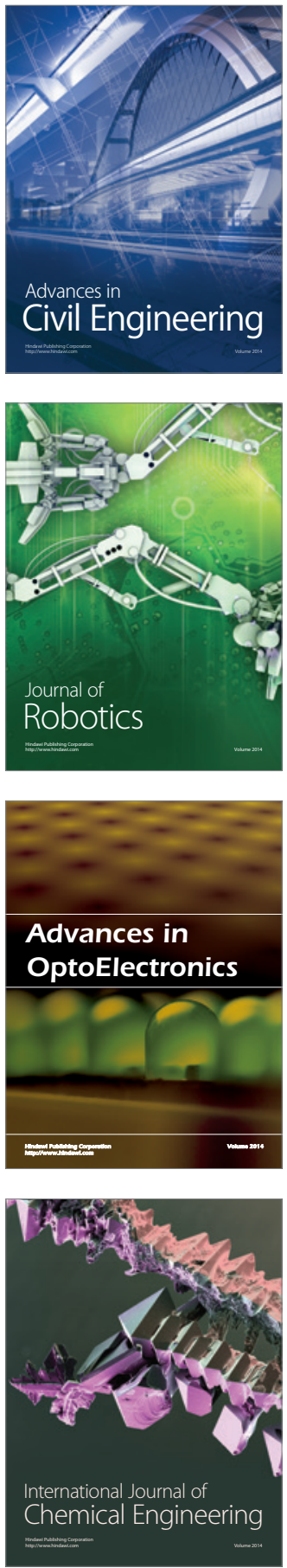

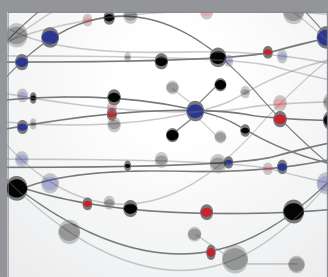

The Scientific World Journal

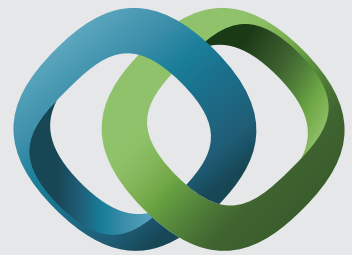

\section{Hindawi}

Submit your manuscripts at

https://www.hindawi.com
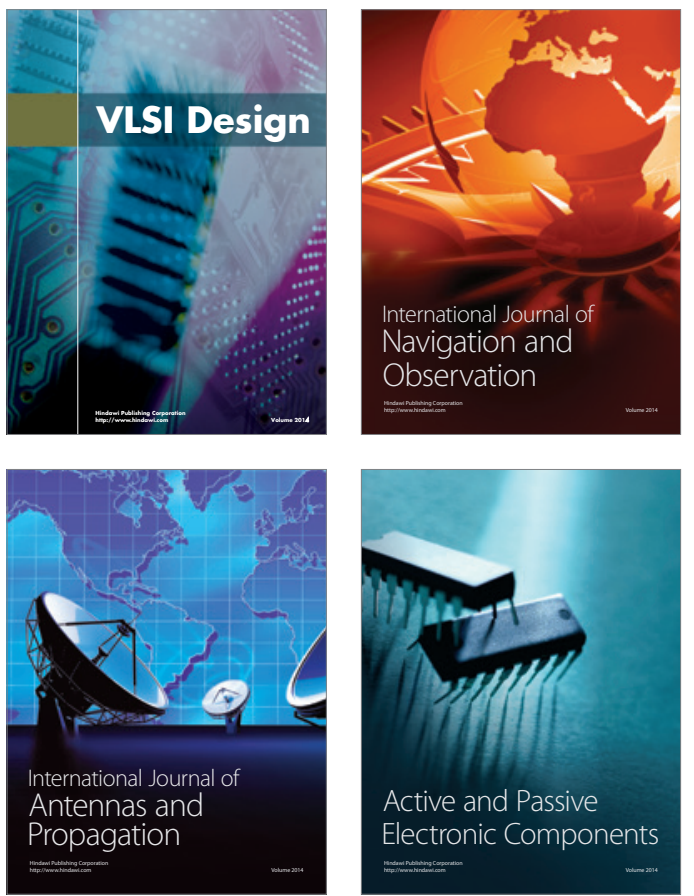
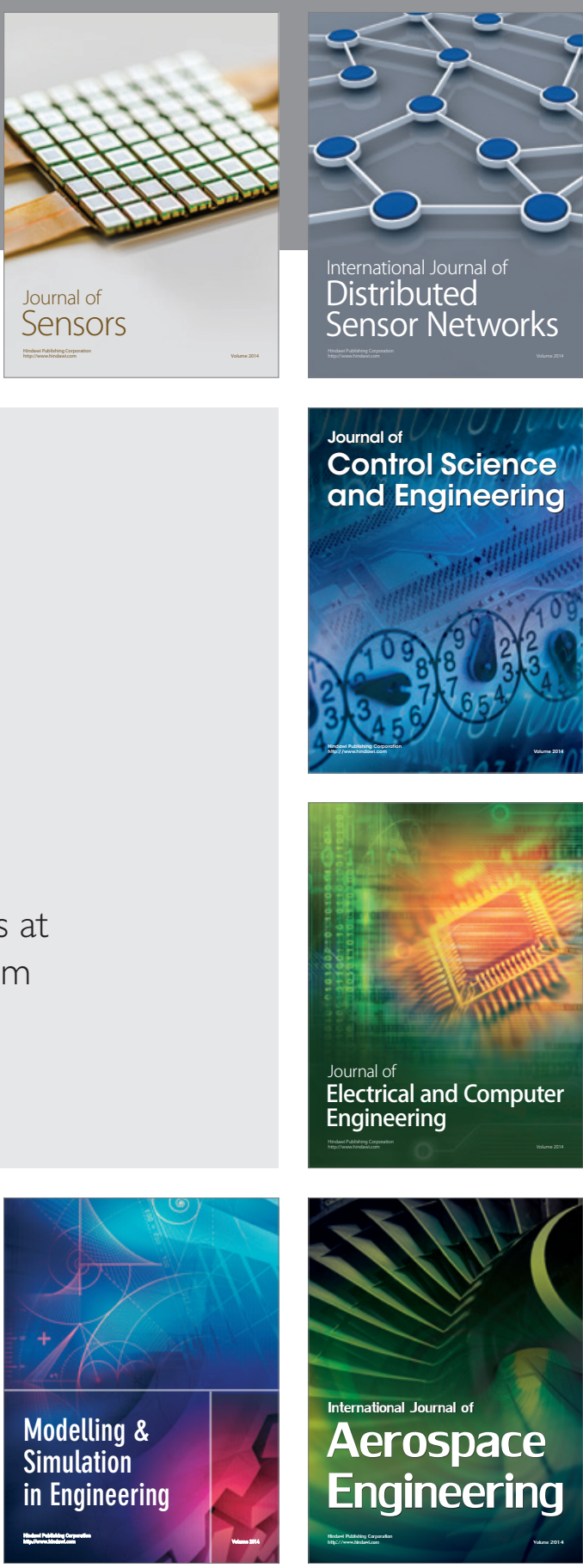

International Journal of

Distributed

Sensor Networks

$-$

Joumal of

Control Science

and Engineering
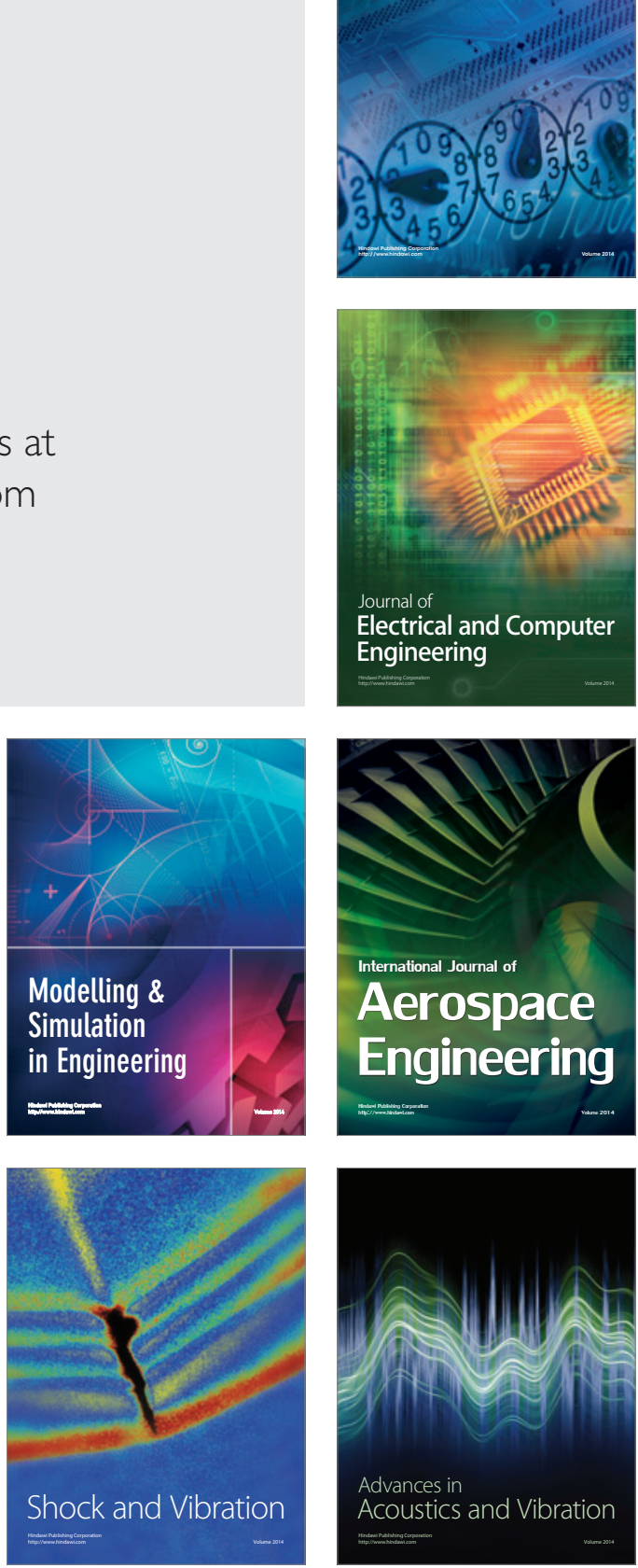